\title{
Drug-induced permeabilization of parasite's digestive vacuole is a key trigger of programmed cell death in Plasmodium falciparum
}

\author{
J-H Ch'ng ${ }^{1}, \mathrm{~K} \mathrm{Liew}^{2}$, AS-P Goh ${ }^{1}$, E Sidhartha ${ }^{1}$ and KS-W Tan ${ }^{\star, 1,2,3}$
}

Having previously characterized chloroquine (CQ)-induced programmed cell death (PCD) hallmarks in the malaria parasite Plasmodium falciparum and delineating a pathway linking these features, the roles of non-classical mediators were investigated in this paper. It was shown that the later stages of this pathway are $\mathrm{Ca}^{2+}$-dependent and transcriptionally regulated. Moreover, it was demonstrated for the first time that micromolar concentrations of $C Q$ partially permeabilized the parasite's digestive vacuole (DV) membrane and that this important upstream event appears to precede mitochondrial dysfunction. This permeabilization of the DV occurred without rupture of the DV membrane and was reminiscent of lysosome-mediated cell death in mammalian cells. As such micromolar concentrations of $C Q$ are found in the patient's plasma after initial $C Q$ loading, this alludes to a clinically relevant antimalarial mechanism of the drug which has yet to be recognized. Furthermore, other 'non-antimalarial' lysosomotropic compounds were also shown to cause DV permeabilization, triggering PCD in both CQ-sensitive and -resistant parasites. These findings present new avenues for antimalarial developments, which induce DV destabilization to kill parasites.

Cell Death and Disease (2011) 2, e216; doi:10.1038/cddis.2011.97; published online 13 October 2011

Subject Category: Experimental Medicine

Although much progress has been made towards controlling and eliminating malaria in some countries, half the world's population continues to be at risk of infection with an estimated one million deaths occurring annually. ${ }^{1}$ Although artesunate-based antimalarials are still effective in treating the disease, resistance to these last-line antimalarials has already been observed near the Thai-Cambodian border, where parasite clearance times have been delayed. ${ }^{2}$ It is therefore essential for new antimalarial leads to be discovered such that therapeutic options stay ahead of resistance development. ${ }^{3}$

We have previously suggested that a novel programmed cell death (PCD) mechanism may be useful in aiding antimalarial design. ${ }^{4}$ Though there have been reports of PCD features occurring in unicellular organisms like Blastocystis, Leishmania, Trypanosoma, Saccharomyces, and Trichomonas, ${ }^{5}$ the existence of such a pathway in Plasmodium remains controversial. PCD features in Plasmodium falciparum $^{6-10}$ and the rodent malaria parasite $P$. berghei $i^{11,12}$ have been documented, characterized by the fragmentation of DNA and a loss of mitochondria membrane potential. However, other reports suggested that Plasmodium does not undergo PCD. ${ }^{6,13,14}$
Accounting in part the discrepancies between these studies, our previous work demonstrated that PCD features were indeed observable in parasites exposed to high micromolar concentrations of chloroquine (CQ) but not at lower nanomolar levels. ${ }^{4}$ Moreover, these features were shown to be linked in a linear pathway: low-levels of cysteine protease activity triggered mitochondrial dysregulation, which preceded the amplification of cysteine protease activity and ultimately led to DNA fragmentation and the parasite's death. Through the use of specific cysteine protease inhibitors, clan CA cysteine proteases were implicated as the key mediators of this pathway, contrary to the hypothesis that clan $C D$ proteases are responsible. ${ }^{8}$ Additionally, the extent of PCD features was shown to vary between different strains, with CQ-resistant parasites showing reduced cell death features than CQ-sensitive parasites when exposed to the same dose of $C Q$.

This study began with the identification of other 'nonclassical' mediators involved in this CQ-induced PCD pathway through the use of various inhibitors of cell death, and later stages were shown to be $\mathrm{Ca}^{2+}$-dependent and transcriptionally regulated. The role of the parasite's digestive vacuole (DV) in facilitating this cell-death pathway was also

\footnotetext{
${ }^{1}$ Department of Microbiology, National University of Singapore, Singapore, Singapore; ${ }^{2}$ Singapore-MIT Alliance for Research and Technology, National University of Singapore, Singapore, Singapore and ${ }^{3}$ Infectious Disease Program, National University of Singapore, Singapore, Singapore

${ }^{*}$ Corresponding author: KS-W Tan, Department of Microbiology, National University of Singapore, 5 Science Drive 2, Singapore 117597, Singapore.

Tel: + 656516 6780; Fax: + 656776 6872; E-mail: mictank@nus.edu.sg

Keywords: malaria; Plasmodium falciparum; programmed cell death; digestive vacuole; lysosomal membrane permeabilization; chloroquine

Abbreviations: PCD, programmed cell death; CQ, chloroquine; DV, digestive vacuole; PPC-KO, pre-procathepsin c knockout; ROS, reactive oxygen species; RNS, reactive nitrogen species; CM-CQ, coumarin-labelled chloroquine; TEM, transmission electron microscopy; $\Delta \psi_{\mathrm{m}}$, mitochondria transmembrane potential; LMP, lysosomal membrane permeabilization; PBN, phenyl-tert-butylnitrone; DSP, desipramine; CPZ, chlorpromazine; PMZ, promethazine; 4HT, 4-hydroxytamoxifen; LL-OMe, Leucine-Leucine-O-Methyl Ester

Received 11.5.11; revised 25.7.11; accepted 30.8.11; Edited by M Piacentini
} 
investigated and it was demonstrated for the first time that the destabilization of this organelle with lysosomotropic compounds led to PCD in the parasite. This is reminiscent of the lysosomal membrane permeabilization (LMP)-associated PCD pathway well studied in mammalian cell lines. Unlike $\mathrm{CQ}$, treatment with these lysosomotropic compounds led to PCD features, which were consistent between CQ-resistant and -sensitive parasite strains, suggesting that such an antimalarial strategy would likely be effective even against CQ-resistant parasites.

\section{Results}

Inhibitors of $\mathbf{C Q}$-induced PCD. To further characterize mediators in the CQ-induced PCD pathway, 3D7 parasites were pre-treated with a panel of inhibitors at various concentrations for $30 \mathrm{~min}$ before being induced with $\mathrm{CQ}$. This panel of inhibitors consisted of calcium chelator BAPTA $(1-100 \mu \mathrm{M})$, clan CD cysteine protease-specific inhibitor Q-VD-OPh (10-50 $\mu \mathrm{M})$, V-ATPase inhibitor bafilomycin A1 that inhibits the acidification of the DV $(10 \mathrm{nM}-1 \mu \mathrm{M})$, calpain inhibitor calpastatin $(10 \mathrm{nM}-10 \mu \mathrm{M})$, reactive nitrogen species (RNS) scavenger phenyl-tert-butylnitrone (PBN, $10 \mu \mathrm{M}-$ $10 \mathrm{mM}$ ), reactive oxygen species (ROS) scavengers glutathione and mannitol $(10 \mu \mathrm{M}-10 \mathrm{mM}$ for both), translation inhibitor cycloheximide $(1-50 \mu \mathrm{M})$ and transcription inhibitor actinomycin $\mathrm{D}(1-50 \mu \mathrm{M})$. Cells were then costained with $\mathrm{JC}-1$ and Hoechst, and assayed for loss of mitochondria transmembrane potential $\left(\Delta \psi_{\mathrm{m}}\right)$ and DNA loss, respectively.

None of the inhibitors tested reduced the proportion of parasites showing loss of $\Delta \psi_{\mathrm{m}}$ (data not shown). It is therefore unlikely that any of the suspected mediators are involved in causing mitochondrial dysregulation in CQ-induced PCD.

Most of the compounds tested did not affect DNA degradation (data not shown), except for BAPTA, cycloheximide and actinomycin $D$, which significantly reduced the proportion of cells showing sub-G1 DNA content (Figure 1). This suggested that DNA degradation, a late-stage feature of the pathway, is dependent on $\mathrm{Ca}^{2+}$ and is also transcriptionally regulated. Furthermore, the involvement of calpains and clan CD cysteine proteases like metacaspase appears unlikely as calpastatin and Q-VD-OPh were ineffective inhibitors.

Microarray data and validation. Microarray analyses of these parasites were performed to elucidate differentially transcribed genes. Of the genes that were dysregulated (Supplementary Data, Supplementary Table S1), a cathepsin c precursor (PFL2290w) was found to be more highly transcribed (6.54-fold increase) at $8 \mathrm{~h}$ after treatment. Realtime RT-PCR was performed to verify this (Supplementary Data, Supplementary Figure S2).

\section{Pre-procathepsin c knockout and corresponding PCD} profile. A 3D7-pre-procathepsin c knockout (PPC-KO) strain was generated (Supplementary Data, Supplementary Figure S3), but JC1 and Hoechst-loss assays on the KO strain showed no difference with the wild type (data not shown). This may have been a result of redundancy of

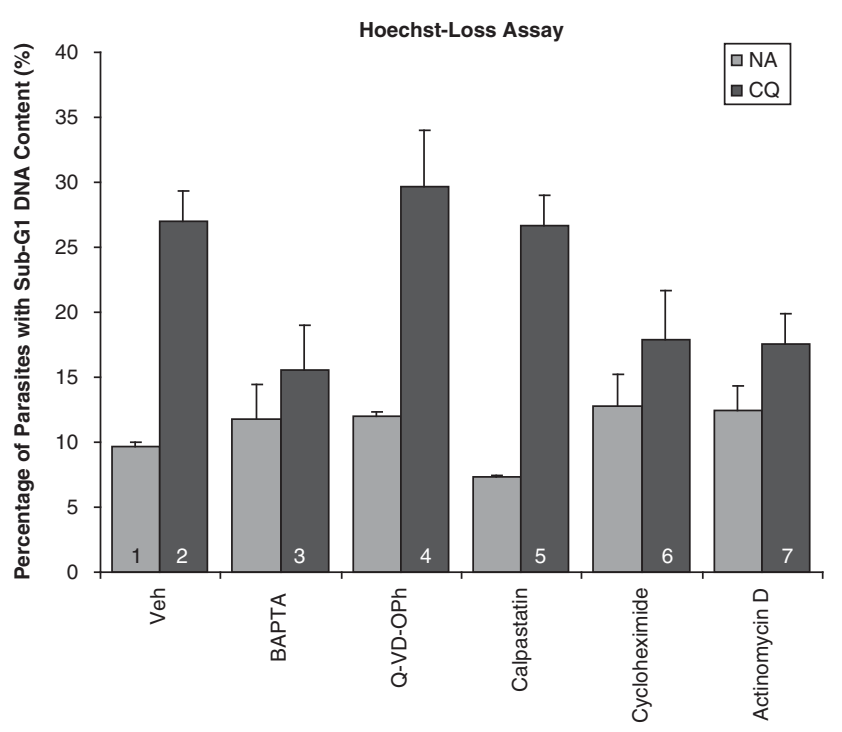

Figure 1 Hoechst-stained 3D7 parasites showing sub-G1 DNA content. The proportion of cells with weak Hoechst staining was assayed for $10 \mathrm{~h}$ after treatment with or without $30 \mu \mathrm{M} \mathrm{CQ}$. Before this, cultures had been preincubated for $30 \mathrm{~min}$ with the following: Vehicle control, $50 \mu \mathrm{M}$ BAPTA-AM, $50 \mu \mathrm{M}$ Q-VD-OPh, $10 \mu \mathrm{M}$ calpastatin, $25 \mu \mathrm{M}$ of cycloheximide and $10 \mu \mathrm{M}$ of actinomycin D. Cells were analyzed by flow cytometry and weak Hoechst staining was indicative of DNA degradation corresponding to a loss of DNA content leading to the sub-G1 population. Data represents means \pm S.E. (1 versus $2 / 4 / 5, P<0.001 ; 2$ versus 3 , $P<0.001 ; 2$ versus $6 / 7, P<0.05 ; N=3$ )

mediators as previously suggested, which complicated further characterization of this protease's role in cell death.

Coumarin-labelled $C Q$ and Fluo-4-AM redistribution. Confocal imaging showed that coumarin-labelled $C Q(C M-C Q)$ and Fluo-4-AM colocalize inside the hemazoin-containing DV, when $\mathrm{CM}-\mathrm{CQ}$ was administered at $300 \mathrm{nM}$ (Figures $2 \mathrm{a}$ and $\mathrm{c}$ ). However, at $30 \mu \mathrm{M}$ of $\mathrm{CM}-\mathrm{CQ}$, the labelled drug and Fluo-4AM both dispersed throughout the parasite's cytoplasm (Figures $2 \mathrm{~b}$ and $\mathrm{c}$ ). Coupled with the involvement of clan CA proteases previously demonstrated, ${ }^{4}$ the simultaneous redistribution of both $\mathrm{CM}-\mathrm{CQ}$ and $\mathrm{Ca}^{2+}$ led us to hypothesize that a permeabilization of the DV membrane may be triggering the PCD pathway.

Abrupt $\mathrm{Ca}^{2+}$ redistribution. Time-course studies showed a dramatic redistribution of Fluo-4-AM from the DV, the primary calcium store ${ }^{15}$ to the cytoplasm between the $2-4 \mathrm{~h}$ time-points (Figure $3 \mathrm{a}$ ). This $2-4 \mathrm{~h}$ after treatment window was further narrowed using real-time single-cell tracking, which showed that this redistribution of Fluo-4-AM from the DV to the parasite's cytoplasm occurred very rapidly (within $1 \mathrm{~min}$ ) in cells at about $3-3.5 \mathrm{~h}$ after treatment with $\mathrm{CQ}$ (Figure $3 \mathrm{~b}$ and Supplementary Data, Supplementary Video S4). This observation supported our hypothesis of a DVbreach as an increasing accumulation of lysosomotropic $C Q$ is likely to have reached a threshold at around $3-3.5 \mathrm{~h}$, leading to the DV membrane being compromised. Control cells showed no redistribution of Fluo-4-AM throughout this 
a

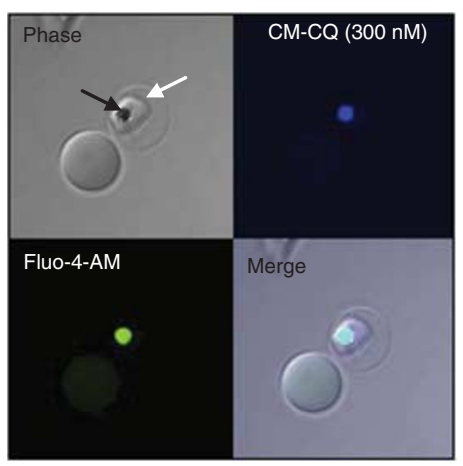

b

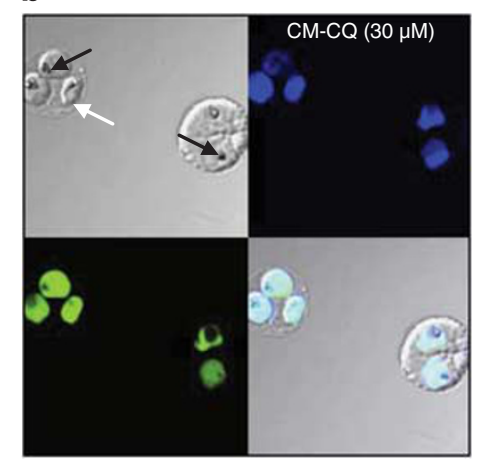

c

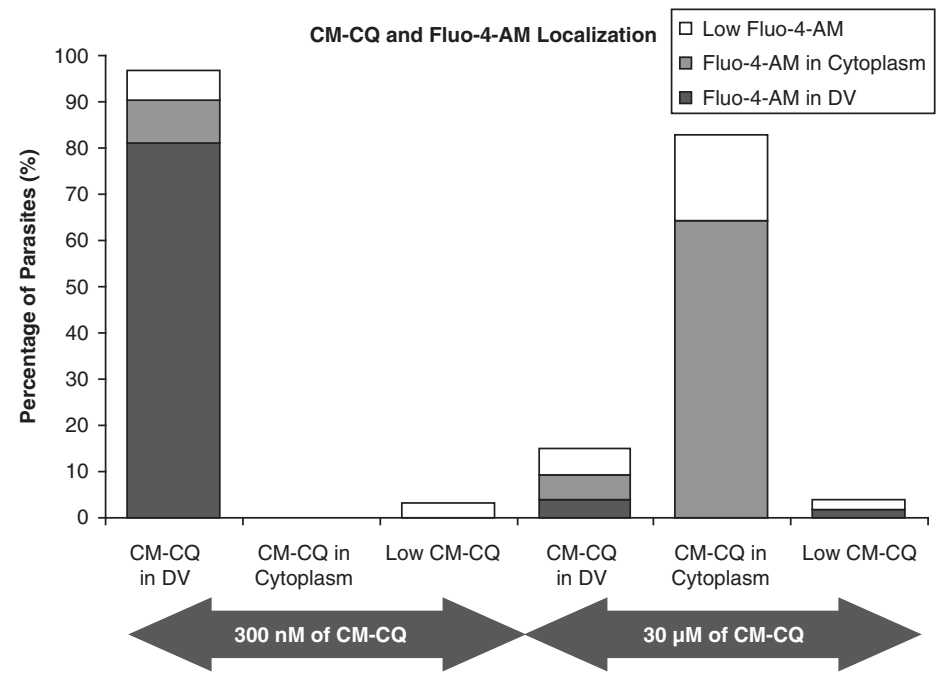

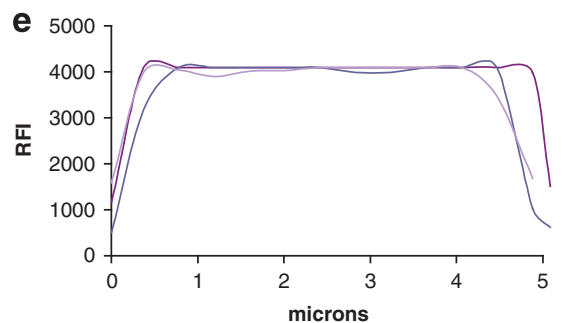

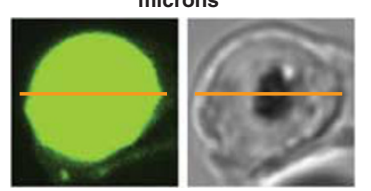

Figure 2 Colocalization studies of CM-CQ and calcium-sensing dye, Fluo-4-AM. (a) 3D7 parasites (white arrows) were treated with $300 \mathrm{nM}$ of CM-CQ for $10 \mathrm{~h}$, stained in Fluo-4-AM and observed by confocal microscopy. Colocalization of CM-CQ and Fluo-4-AM to the hemazoin-containing DV (black arrows) is clearly seen at such nanomolar concentrations of the drug. (b) Parasites exposed to $30 \mu \mathrm{M}$ of CM-CQ show localization of both $\mathrm{CM}-\mathrm{CQ}$ and Fluo-4-AM to the cytoplasm of the parasite but not the cytoplasm of the host erythrocyte. (c) At least 50 parasites were counted and the results were tabulated to show the association in the localization of Fluo-4-AM and CM-CQ. (d) Fluorescence intensity traces of the cross-section (yellow) of three representative uninduced parasitized erythrocytes stained with Fluo-4-AM shows that the hemazoincontaining DV is intensely stained. (e) The fluorescent trace of three representative induced parasites ( $3 \mu \mathrm{M}$ of $\mathrm{CQ}$ for $4 \mathrm{~h}$ ) shows that Fluo-4-AM fluorescence is distributed throughout the length of the parasite cross-section

period, and the fluorescence signal was not compromised by photobleaching (data not shown).

To validate this model further, $\mathrm{CQ}$-resistant strains bearing the CQ-resistance transporter (PfCRT) mutation were also investigated. Interestingly, 7G8 parasites showed a similar staining profile to that of $3 \mathrm{D} 7$ after $4 \mathrm{~h}$ exposure to $3 \mu \mathrm{M}$ of $\mathrm{CQ}$, while K1 showed a markedly reduced proportion of cells with Fluo-4-AM redistributed to the cytoplasm (Figure $3 \mathrm{c}$ ). This is likely due to differences in the PfCRT mutations and will be discussed later. 
a

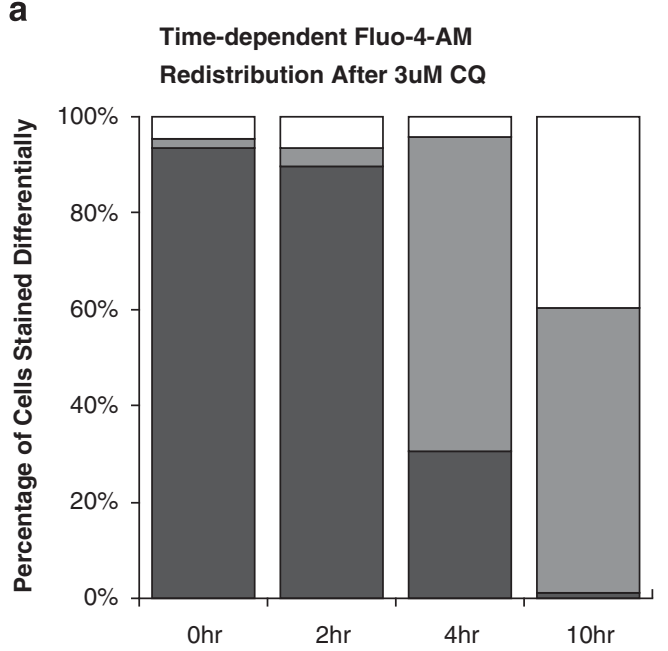

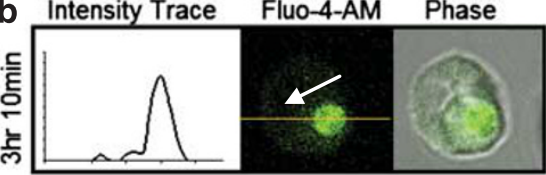
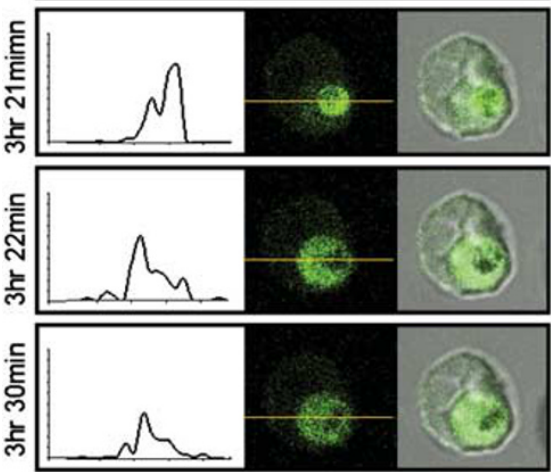

C

Fluo-4-AM Redistribution 4hrs After 3uM CQ

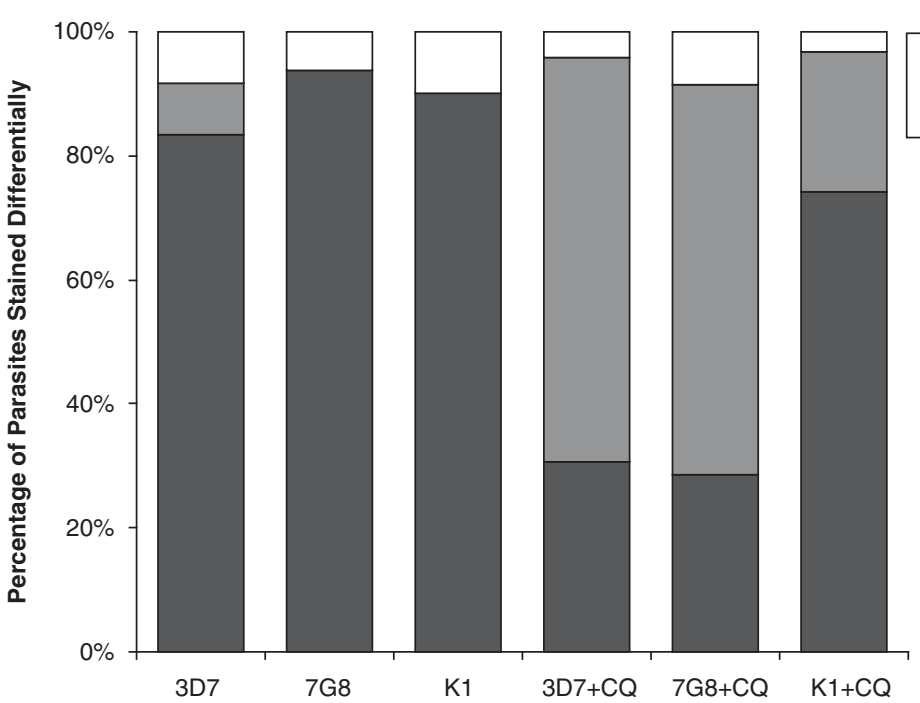

$\square$ Unstained

$\square$ Cytoplasmic Staining

口 Digestive Vacuole Staining

Figure $3 \mathrm{CQ}$-induced $\mathrm{Ca}^{2+}$-redistribution assays. (a) $3 \mathrm{D} 7$ parasites were treated with $3 \mu \mathrm{M}$ of $\mathrm{CQ}$ for various time-points, stained with Fluo-4-AM and observed by confocal microscopy. Calcium-sensing Fluo-4-AM showed widespread redistribution from the parasite DV to the cytoplasm between 2 and $4 \mathrm{~h}$. (b) Video grabs from live cell imaging experiments shows a Fluo-4-AM-stained parasite that was immobilized on a poly-lysine-treated glass chamber and exposed to $3 \mu \mathrm{M}$ of $\mathrm{CQ}$ and tracked for up to $4 \mathrm{~h}$. Fluo-4-AM initially localizes to the DV (white arrow) but later redistributes to the parasite cytoplasm. Fluorescence intensity trace of the parasite's cross-section (yellow) shows a clear shift in the Fluo-4-AM staining profile from the DV to the entire cytoplasm. (c) $C Q$ at $3 \mu \mathrm{M}$ also resulted in Fluo-4-AM redistribution in CQ-resistant 7G8 and K1 parasite strains after $4 \mathrm{~h}$ exposure, but to a reduced degree in $\mathrm{K} 1$. At least 30 infected erythrocytes were counted per condition

Transmission electron microscopy. To determine whether the DV membrane had been affected as a result of CQ-treatment, ultrastructures of saponin-enriched 3D7 parasites were analyzed. In healthy control parasites, the DV membrane was clearly stained and formed a continuous boundary enveloping the hemazoin crystals (Figure 4ai and ii). In CQ-treated cells, a variety of cell morphologies were observed after $4 \mathrm{~h}$ incubation. A majority of cells appeared similar to the healthy control cells with visible and continuous membrane surrounding the DV (Figure 4bi and ii). However, their hemazoin crystals were less well defined and membranous whorls or vacuoles appeared within the DV. Occasionally, cells showed DV with electron-lucent membrane with some having minute breaks showing DV material being extruded into the cytoplasm (Figure 4ci-iii). In a few cells, a massive rupture of the DV membrane was observed, leading to DV contents being emptied into the parasite's cytoplasm (Figure 4d) - these are likely to be necrotic cells.

Mitochondria dysregulation and DNA degradation induced by lysosomotropic compounds. The JC-1 and Hoechst assay were used to screen a variety of potential DV-permeabilizing compounds through a range of concentrations: Leu-Leu-OMe (LL-OMe, $100 \mathrm{nM}-10 \mathrm{mM}$ ), norfloxacin $(100 \mathrm{nM}-100 \mu \mathrm{M})$, ciprofloxacin $(250 \mu \mathrm{M}-$ $10 \mathrm{mM})$, miltefosine $(100 \mathrm{nM}-200 \mu \mathrm{M})$, vincristine $(50 \mathrm{nM}-$ $10 \mu \mathrm{M})$, verapamil (VP, 1-200 $\mu \mathrm{M})$, diltiazem (1-200 $\mu \mathrm{M})$, 
a i.

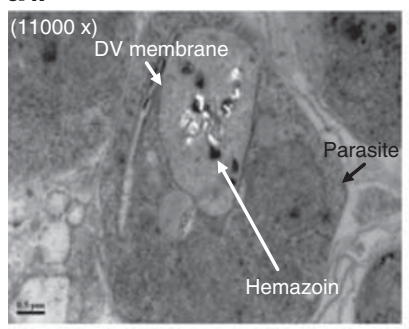

ii.

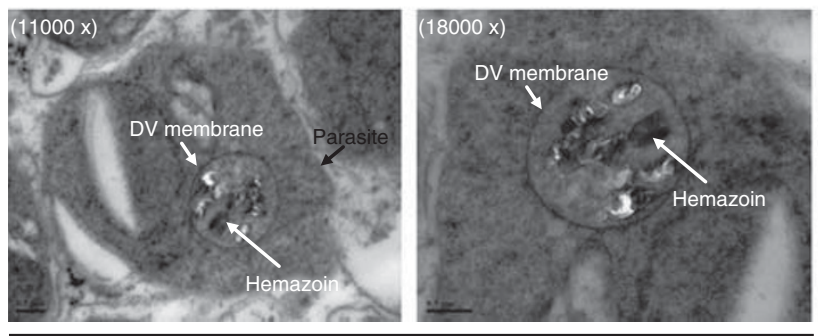

ci.

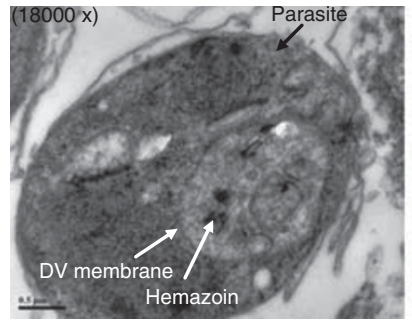

ii.
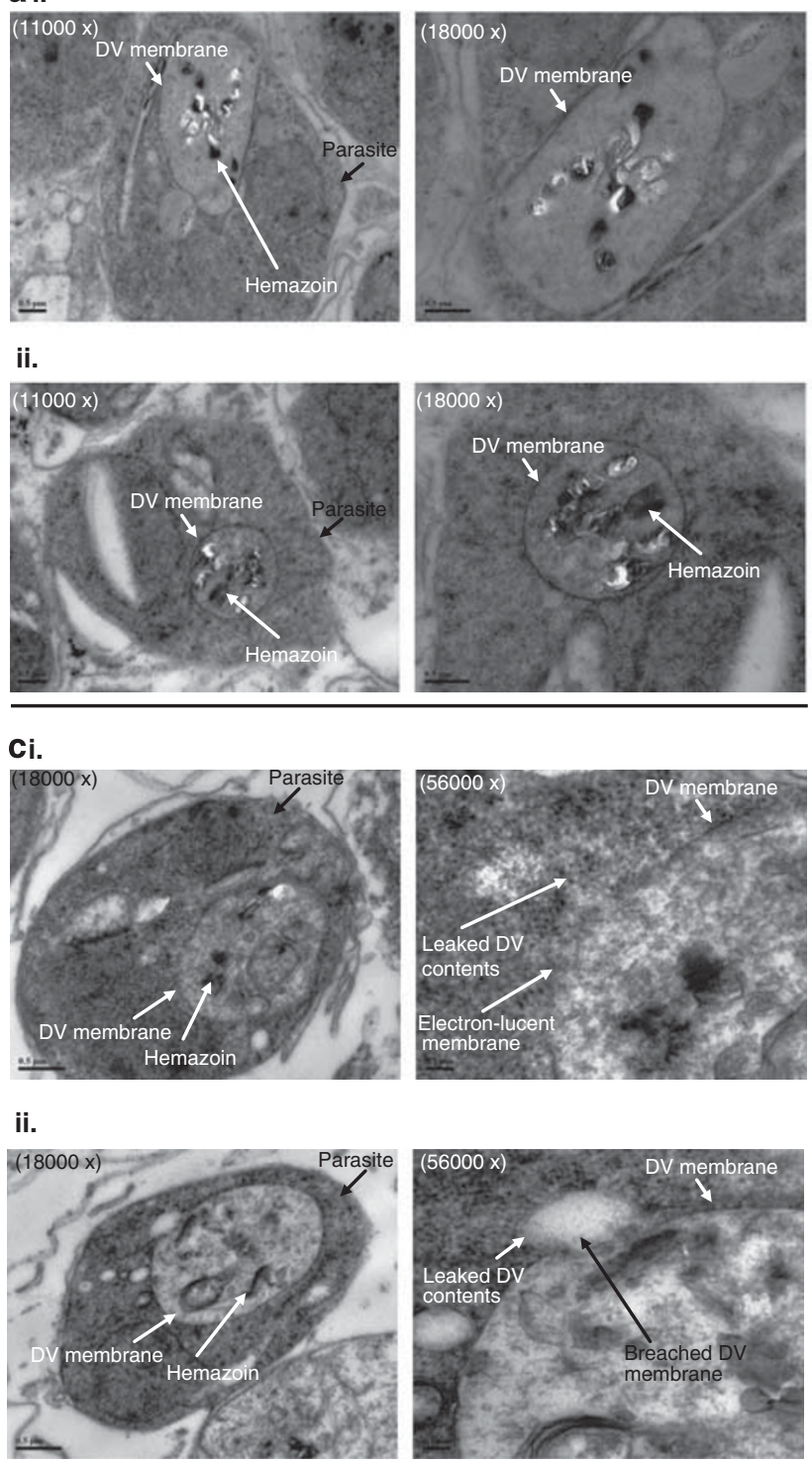

bi.
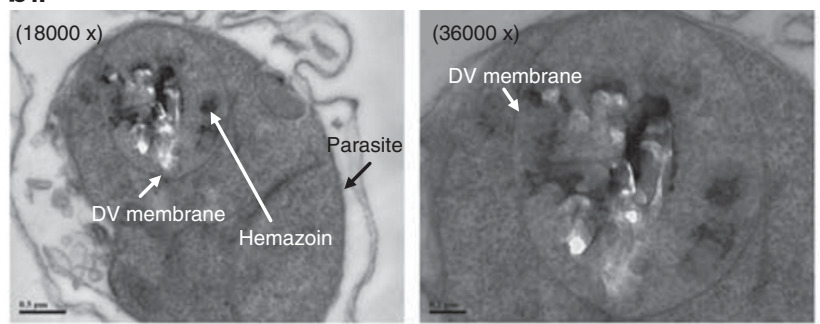

ii.

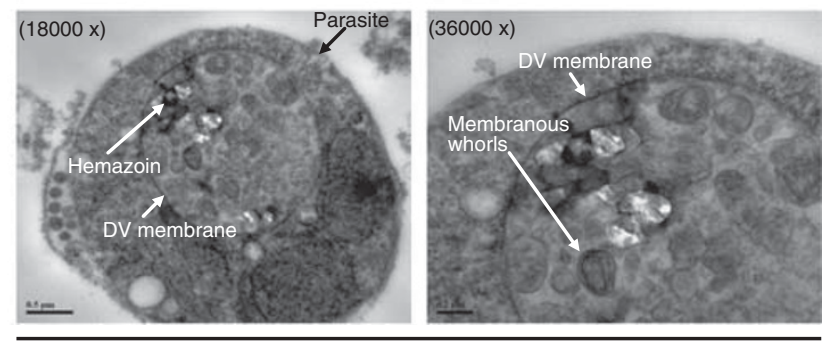

iii.
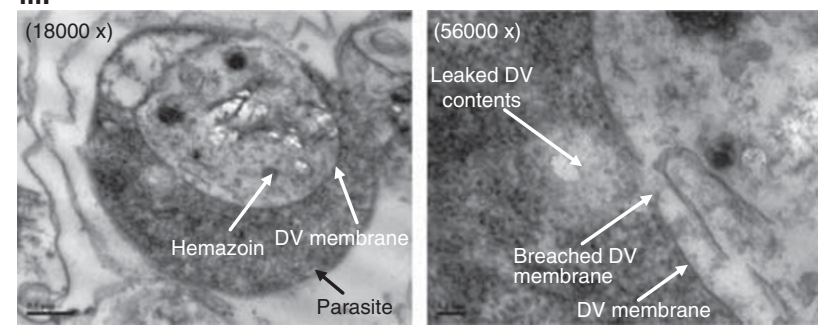

d

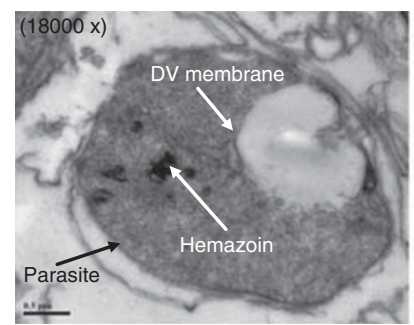

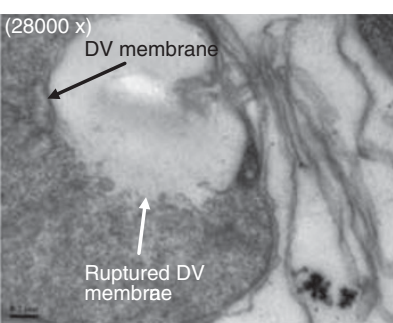

Figure 4 TEM of 3D7 parasites. (ai and ii) Untreated 3D7 parasites show clearly defined hemazoin crystals located within an intact DV membrane. (bi and ii) Parasites exposed to $3 \mu \mathrm{M}$ of CQ for $4 \mathrm{~h}$ also show intact DV membrane but with less discrete hemazoin crystals and membrane whorls forming inside the DV. (ci-iii) Some of the treated parasites also show compromised DV membrane with DV material extruding into the cytoplasm. (d) Other CQ-treated parasites show DV rupture leading to hemazoin crystals being dispersed into the cytoplasm. Scale bar shows $0.5 \mu \mathrm{m}$ for $\times 11000$ and $\times 18000$ magnifications, $0.2 \mu \mathrm{m}$ for $\times 28000$ and $\times 36000$ magnifications, and $0.1 \mu \mathrm{m}$ for $\times 56000$ magnification

desipramine (DSP, 1-200 $\mu \mathrm{M})$, chlorpromazine (CPZ, $10 \mathrm{nM}-200 \mu \mathrm{M})$, promethazine (PMZ, $10 \mathrm{nM}-200 \mu \mathrm{M})$, 4-hydroxytamoxifen (4HT, $10 \mathrm{nM}-200 \mu \mathrm{M})$, propranolol $(1 \mathrm{nM}-200 \mu \mathrm{M})$ and chlorpheniramine $(1 \mathrm{nM}-200 \mu \mathrm{M}$; data not shown).

Of the five compounds, which showed significant PCD features in 3D7 after $10 \mathrm{~h}$ incubation, the lowest concentration of the compound at which the features were detected was used on 7G8 and $\mathrm{K} 1$ as well (Figures $5 \mathrm{a}$ and b). Their concentrations are as follows: $200 \mu \mathrm{M}$ DSP, $100 \mu \mathrm{M} \mathrm{CPZ}$, $200 \mu \mathrm{M} \mathrm{PMZ}, 150 \mu \mathrm{M} 4 \mathrm{HT}$ and $10 \mathrm{mM}$ LL-OMe (due to its limited solubility, the concentration of Leu-Leu could not be increased beyond this even though the PCD features were not extensive).
As previously accounted for, ${ }^{4} \mathrm{CQ}$ caused $3 \mathrm{D} 7$ and $7 \mathrm{G} 8$ parasites to undergo loss of $\Delta \psi_{\mathrm{m}}$ but to a lesser extent in $7 \mathrm{G} 8$ parasites, while the proportion of $\mathrm{K} 1$ parasites exhibiting loss of $\Delta \psi_{\mathrm{m}}$ was unaffected (Figure $5 \mathrm{a}$ ). In contrast, DSP, CPZ, PMZ, $4 \mathrm{HT}$ and LL-OMe were all shown to be effective in causing loss of $\Delta \psi_{\mathrm{m}}$ in 3D7, $7 \mathrm{G} 8$ and K1 (Figure 5a). Notably, their effects were different between strains, but CQ-resistant 7G8 and K1 parasites were either equally or more sensitive to the effects of these lysosomotropic compounds than CQ-sensitive 3D7.

Similarly, CQ caused DNA degradation in all three strains of parasites, but to a lesser degree in $\mathrm{K} 1$ and $7 \mathrm{G} 8$ strains (Figure 5b). In comparison, DSP, CPZ, PMZ and 4HT were all effective in causing DNA degradation in all three strains (Figure 5b). 

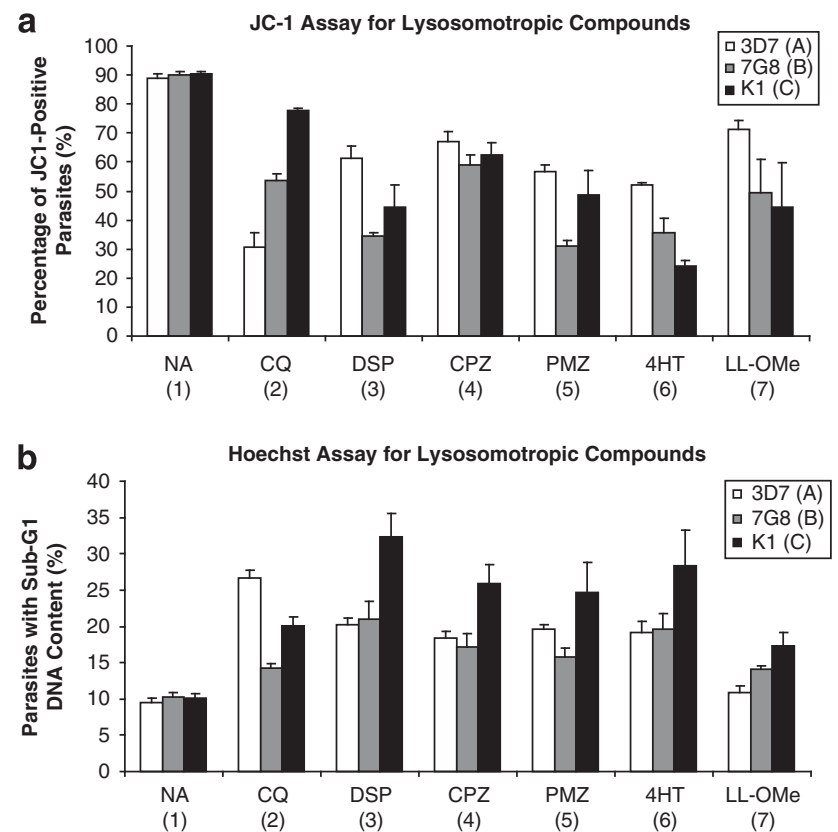

Figure $5 \mathrm{PCD}$ features in parasites exposed to lysosomotropic compounds. CQ-sensitive $3 \mathrm{D} 7$ and $\mathrm{CQ}$-resistant $7 \mathrm{G} 8$ and $\mathrm{K} 1$ parasites were exposed to a

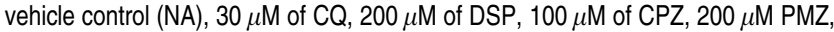
$150 \mu \mathrm{M}$ of $4 \mathrm{HT}$ or $10 \mathrm{mM}$ LL-OMe for $10 \mathrm{~h}$ before staining with $\mathrm{JC}-1$ and Hoechst, and analysis by flow cytometry. (a) JC-1 staining shows mitochondrial outermembrane permeabilization in treated parasites. Data represent means $\pm S$.E. (A1 versus $\mathrm{A} 2-\mathrm{A} 7, \mathrm{P}<0.001$; $\mathrm{B} 1$ versus $\mathrm{B} 2-\mathrm{B} 7, \mathrm{P}<0.001$; $\mathrm{C} 1$ versus $\mathrm{C} 3-\mathrm{C} 7$, $P<0.001 ; N=3$ ). (b) Weak Hoechst staining shows parasites with sub-G1 DNA content after exposure to lysosomotropic compounds. Data represent means \pm S.E. (A1 versus A2-A6, $P<0.001$; $\mathrm{B} 1$ versus $\mathrm{B} 2, P<0.05$; $\mathrm{B} 1$ versus $\mathrm{B} 3-\mathrm{B} 6$, $P<0.001$, B1 versus $\mathrm{B} 7, P=0.053 ; \mathrm{C} 1$ versus $\mathrm{C} 2, P<0.01 ; \mathrm{C} 1$ versus $\mathrm{C} 3-\mathrm{C} 6$, $P<0.001 ; C 1$ versus $C 7, P=0.072 ; N=3$ )

These results demonstrated that the extent of $C Q$-induced PCD is dependent on PfCRT mutations, whereas PCD induced by DSP, CPZ, PMZ and $4 \mathrm{HT}$ is unaffected by PfCRT mutations and consistently triggers a significant degree of loss of $\Delta \psi_{\mathrm{m}}$ and DNA degradation in all three strains.

$\mathrm{Ca}^{2+}$ redistribution in 3D7, 7G8 and $\mathrm{K} 1$ induced by $\mathrm{CQ}$ and other lysosomotropic compounds. Treatments with DSP, CPZ, PMZ or 4HT resulted in Fluo-4-AM redistribution from the hemazoin-containing parasite DV to the parasite's cytoplasm in all three strains (Figures $6 \mathrm{a}-\mathrm{C}$ ), similar to what had been observed in Figures 2 and 3. This simultaneous occurrence of DV permeabilization and PCD features suggests that these are coupled events, and supports the hypothesis that leakage of clan CA cysteine proteases from the DV triggered the hallmark PCD features.

$\mathrm{IC}_{50}$ of lysosomotropic compounds. The $\mathrm{IC}_{50}$ values of $\mathrm{CQ}$ for 3D7, 7G8 and $\mathrm{K} 1$ were determined to be $48 \mathrm{nM}$, $170 \mathrm{nM}$ and $355 \mathrm{nM}$, respectively (Figures $7 \mathrm{a}-\mathrm{c}$ ), while the $\mathrm{IC}_{50}$ values for the other lysosomotropic compounds were determined to range from $5.024-27.563 \mu \mathrm{M}$. Interestingly, CQ-resistant strains appeared equally or more susceptible to these compounds than the CQ-sensitive strains. At this point, there is insufficient data to address the causes or implications of these differences.

\section{Discussion}

We have previously reported evidence that micromolar levels of $C Q$ initiate a unique $P C D$ pathway that involves the activity of clan CA cysteine proteases, loss of $\Delta \psi_{\mathrm{m}}$, DNA fragmentation and cell death. ${ }^{4}$ This paper begins by further characterizing this pathway through the use of inhibitors to non-classical PCD mediators.

Even though some studies have shown that ROS and RNS exposure resulted in parasites with cell death characteristics, ${ }^{6,10,13}$ we were unable to detect their involvement in the $\mathrm{CQ}$-induced PCD pathway. Although $\mathrm{Ca}^{2+}$-chelating BAPTA-AM was able to reduce DNA degradation, experiments involving calpastatin were unable to show calpain involvement as had been proposed by others. ${ }^{16,17}$ Clan CD-specific cysteine protease inhibitor, Q-VD-OPh, was also ineffective in reducing $P C D$ features in $C Q$-induced parasites even though the role of a parasite metacaspase (PfMCA $1-\mathrm{a} \mathrm{Ca}^{2+}$-sensitive clan CD cysteine protease) had been proposed by others. ${ }^{8}$

Notably, it was demonstrated for the first time that CQ-induced cell death had a transcriptionally regulated component - cycloheximide and actinomycin pre-treatment reduced the proportion of parasites showing sub-G1 DNA content. This suggests that the late stage of cell death may, at least in part, rely on transcriptionally dependent mechanisms.

Microarray data of $C Q$-treated parasites showed that a number of cysteine proteases were indeed upregulated, including a putative clan CA pre-procathepsin $c$ gene. However, knockout parasites were not more resistant to $P C D$, and these inconclusive results may suggest that redundancy factors are involved.

Recognizing that clan CA cysteine proteases are typically localized to the parasite's DV and that they are associated with haemoglobin digestion, ${ }^{18,19}$ it was possible their redistribution to the cytoplasm may trigger/mediate CQ-induced PCD. This would require that the DV membrane becomes permeabilized and that DV-localizing moieties (such as $\mathrm{Ca}^{2+}$ ) to be released together with these proteases. ${ }^{15}$ Indeed, a simultaneous redistribution of both CM-CQ and $\mathrm{Ca}^{2+}$ out of the DV was observed, but this only occurred at micromolar concentrations of $C M-C Q$. This was not surprising as $C Q$ is known to be lysosomotropic, and its excessive accumulation in the parasite DV may have led to a destabilization of the DV membrane. Such permeabilization of lysosome membrane has also been demonstrated in mammalian cells exposed to micromolar concentrations of $\mathrm{CQ} .{ }^{20-22}$

The physiological relevance of $\mathrm{Ca}^{2+}$ redistribution in the regulation of $P$. falciparum and $P$. chabaudi development has been demonstrated previously by the Garcia group. ${ }^{16,17,23,24}$ It was shown that high levels of melatonin, a hormone regulated by the circadian cycle, resulted in phospholipases $C$ activation, the generation of $\mathrm{IP}_{3}$ and a release of $\mathrm{Ca}^{2+}$ from the intracellular ER-stores, eventually leading to the loss of parasite synchronization. ${ }^{23,25}$ Moreover, the redistribution of $\mathrm{Ca}^{2+}$ was accompanied by an increase in mitochondria $\mathrm{Ca}^{2+}$ levels ${ }^{26}$ and an increase in the activity of cysteine proteases within the parasite's cytoplasm. ${ }^{16}$ It would be interesting to 
a

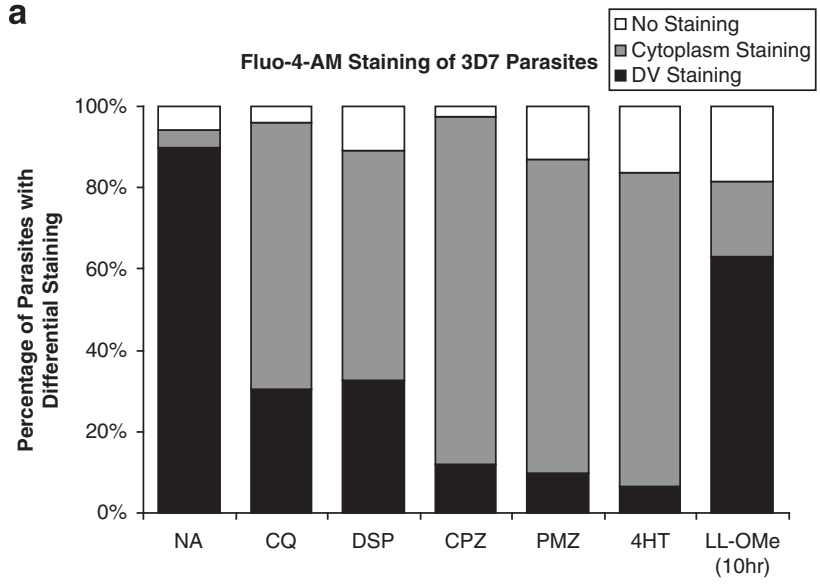

b

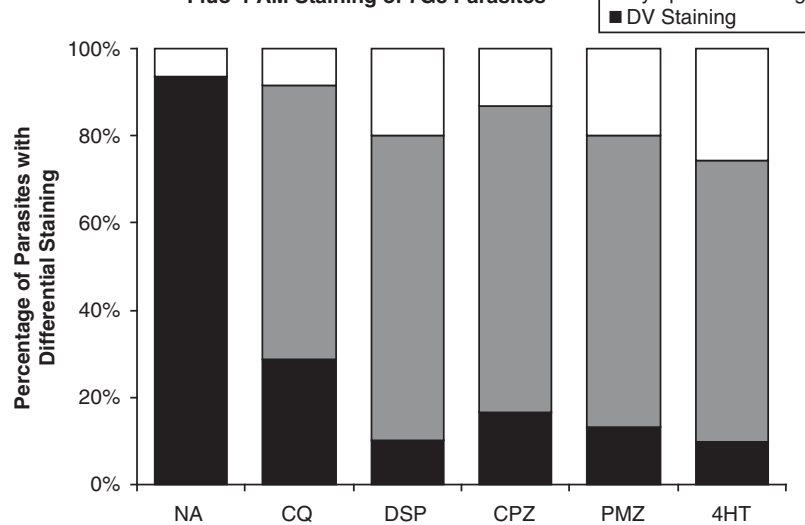

C

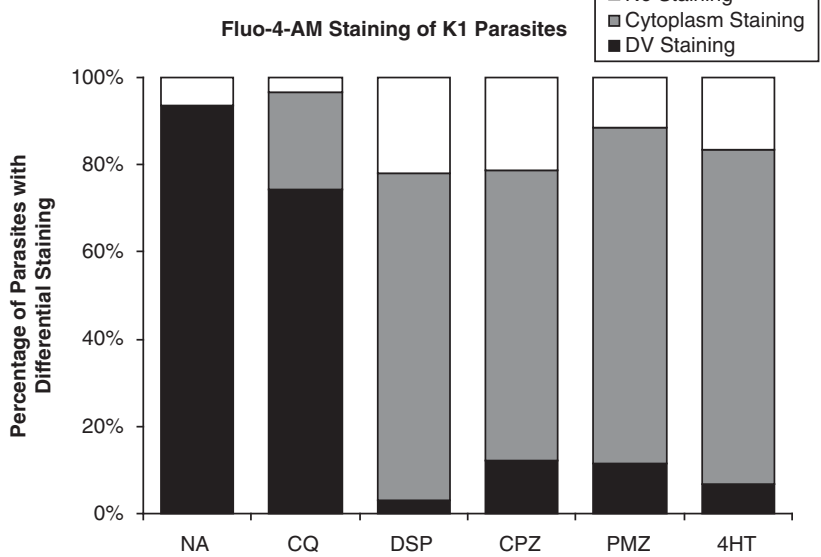

Figure 6 Effect of lysosomotropic compounds on $\mathrm{Ca}^{2+}$-localization. Parasites were exposed to a vehicle control (NA), $3 \mu \mathrm{M}$ of $\mathrm{CQ}, 200 \mu \mathrm{M}$ of DSP, $100 \mu \mathrm{M}$ of $\mathrm{CPZ}, 200 \mu \mathrm{M} \mathrm{PMZ}, 150 \mu \mathrm{M}$ of $4 \mathrm{HT}$ for $4 \mathrm{~h}$, or $10 \mathrm{mM}$ LL-OMe for $10 \mathrm{~h}$ before staining with $\mathrm{Ca}^{2+}$-sensing Fluo-4-AM and observation under a confocal microscope. (a) CQ-sensitive 3D7 and (b) CQ-resistant $7 \mathrm{G} 8$ show similar redistribution of Fluo-4-AM from the hemazoin-containing DV to the parasite's cytoplasm after exposure to CQ, DSP, CPZ, PMZ and 4HT. (c) Multi drug-resistant $\mathrm{K} 1$ parasites, however, shows decreased redistribution after exposure to $C Q$ but similar redistribution when exposed to the other lysosomotropic compounds. At least 30 infected erythrocytes were counted per condition study the possible role of $\mathrm{Ca}^{2+}$-associated PCD in the in vivo synchronization of parasites that results in the characteristic cycle of fever and chills in afflicted patients.

To better understand the mechanics of the permeabilization, time-course experiments were performed and the study was extended to include CQ-resistant $7 \mathrm{G} 8$ and $\mathrm{K} 1$ parasite strains. Interestingly, DV destabilization was identified to occur in a majority of 3D7 and 7G8 parasites between 2 and $4 \mathrm{~h}$ after exposure to $3 \mu \mathrm{M}$ of $\mathrm{CQ}$, whereas only a minority of $\mathrm{K} 1$ parasites exhibited this. This is likely due to the effects of the PfCRT in reducing $C Q$ levels within the DV of $K 1$ and thereby stabilizing it. As can be seen from the lower $I C_{50}$ value, the PfCRT of $7 \mathrm{G} 8$ is less efficient that in $\mathrm{K} 1$ and may not have adequately effluxed $C Q$ to stabilize the organelle at such micromolar doses. ${ }^{27}$

The early onset of DV destabilization in the majority of 3D7 parasites after only $2-4 \mathrm{~h}$ suggests that this feature may present before the loss of $\Delta \psi_{\mathrm{m}}$, which was previously shown to occur in only a small proportion of induced parasites 4-6h after $\mathrm{CQ}$ administration. ${ }^{4}$

Through the use of live cell imaging, the redistribution of $\mathrm{Ca}^{2+}$ in 3D7 was observed to occur in an abrupt and rapid manner. This supported a model where the accumulation of Iysosomotropic $C Q$ within the DV reached a threshold beyond which the DV membrane was permeabilized and its contents rapidly leaked into the parasite cytosol. However, this observation does raise concerns about the 'programmed' nature of cell death. Although an unregulated rupture of lysosomes has been shown to result in necrosis in mammalian cell, a regulated LMP has been demonstrated to result in cathepsin-mediated PCD. ${ }^{28-31}$ It was therefore important to closely examine the DV membrane to observe for membrane integrity.

Transmission electron microscopy (TEM) imaging of CQ-treated 3D7 did indeed show a small proportion of parasites with ruptured DVs. This has also been observed in $P$. falciparum subjected to heat shock, and such cells are likely to be necrotic parasites. ${ }^{14}$ Some other cells had minute pores through which DV enzymes may have leaked into the cytoplasm and it cannot be ascertained whether these cells are undergoing regulated or unregulated cell death. A majority of cells, however, showed intact and clearly defined DV membrane. This is in line with other reports showing the cells undergoing LMP often have no observable ultrastructural differences in lysosome membrane morphology when compared with healthy cells. ${ }^{30}$ Given that the majority of CQ-treated parasites also show Fluo-4-AM redistribution to the cytoplasm followed by PCD hallmarks, it is possible that these parasites have 'regulated' membrane permeability leading to $\mathrm{Ca}^{2+}$ release without visible membrane compromise and leading to a 'regulated' PCD pathway.

Although the process of lysosome-mediated cell death has been well studied, the exact mechanisms remain unclear. ${ }^{31}$ One model suggests apoptosis-associated LMP is size selective such that only smaller molecules are able to diffuse through the partially permeable lysosomal membrane while larger molecules remain trapped. ${ }^{32}$ If this model is applicable to $P$. falciparum, it might allow specific clan CA proteases to exit the parasite DV (together with $\mathrm{CM}-\mathrm{CQ}$, and $\mathrm{Ca}^{2+}$ ) and trigger PCD without jeopardizing the DV membrane. 
a

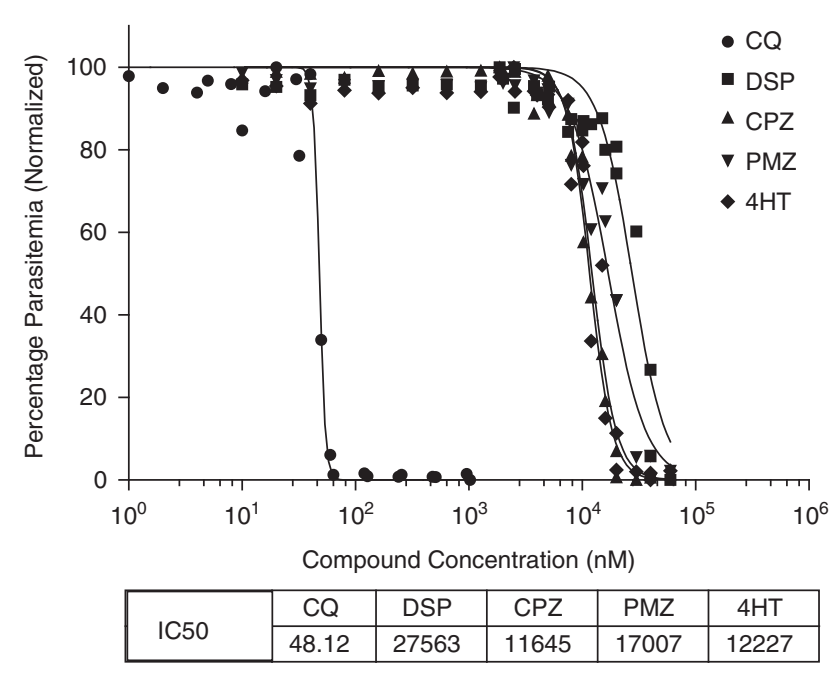

b

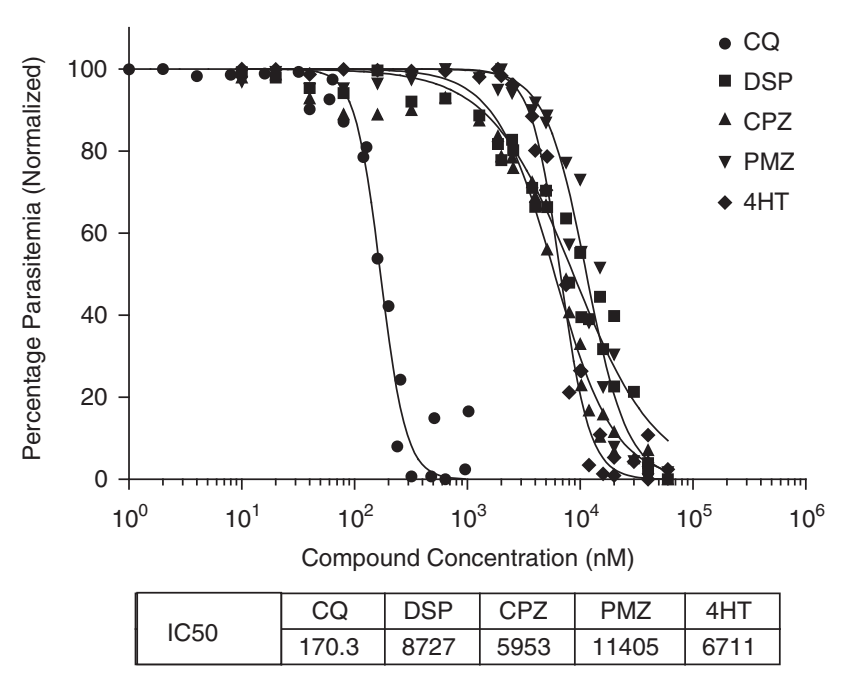

c

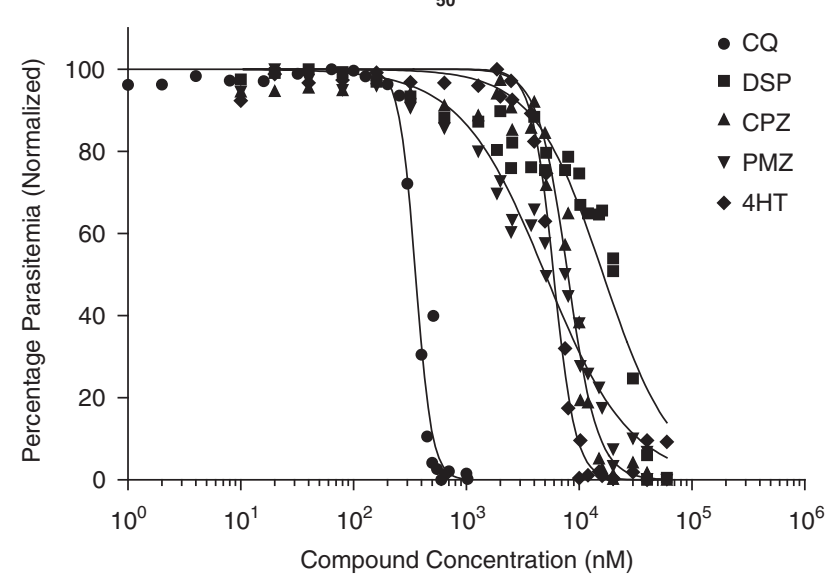

\begin{tabular}{|c|c|c|c|c|c|}
\hline \multirow{2}{*}{ IC50 } & CQ & DSP & CPZ & PMZ & 4 HT \\
\cline { 2 - 6 } & 355.1 & 16366 & 7945 & 5024 & 5952 \\
\hline
\end{tabular}

Notably, this novel discovery of DV permeabilization in response to micromolar concentrations $C Q$ is clinically relevant as serum levels of $C Q$ actually do reach such concentrations. ${ }^{33-35}$ Although the main antimalarial mechanism of $\mathrm{CQ}$ lies in its inhibition of hemazoin formation, DV destabilization may account for the rapid clearance of parasites (especially those at the late-trophozoite and schizont stage) during the initial drug-loading phase of treatment.

To investigate whether PCD is CQ specific or truly a result of DV destabilization, other lysosomotropic compounds were assayed. Of the panel of compounds tested, DSP, CPZ, PMZ and $4 \mathrm{HT}$ all produced both early (loss of $\Delta \psi_{\mathrm{m}}$ ) and late-stage (DNA degradation) hallmarks of PCD. Moreover, confocal microscopy confirmed that these compounds induced DV permeabilization after only $4 \mathrm{~h}$ treatment. Interestingly, these compounds have been shown to be strong lysosomotropic compounds that reduced LysoTracker Red staining and showed cytotoxicity in $\mathrm{H} 9 \mathrm{c} 2$ rat cardiomyocyte-derived cells as well. ${ }^{20}$ The manner in which DV destabilization triggers cell death is also very similar to that described for metazoan cells which have been shown to involve LMP, loss of $\Delta \psi_{m}$ (shown to be an indispensable component of the pathway) and caspaseindependent or -dependent cell death execution. ${ }^{21-22}$

Notably, these compounds function equally well in inducing parasite PCD regardless of $C Q$ sensitivity. This might be expected as the presence of PfCRT and other multi-drug resistant transporters are not expected to affect their accumulation inside the DV. Nevertheless, it should be cautioned that resistance might develop if compound-specific transporters evolve to efflux such drugs out of the DV.

Unlike $C Q$ which primarily exerts its antimalarial activity through inhibiting hemazoin polymerization, ${ }^{36}$ these DV-destabilizing compounds are not known to bind with any specific target and, resultantly, their $\mathrm{IC}_{50}$ values are relatively high $(6-30 \mu \mathrm{M})$ compared with that of $\mathrm{CQ}(48-355 \mathrm{nM})$. Though this limits their usefulness in antimalarial therapy, the high $\mathrm{IC}_{50}$ values of these compounds suggest that these compounds inhibit parasite growth through their lysosomotropic nature - these compounds exert their cytotoxic effects only when they have accumulated to sufficient levels in the DV to alter its biochemistry. That these compounds affect mammalian lysosomes at similar concentrations $(3-40 \mu \mathrm{M})$ is also suggestive of this. ${ }^{20}$ As micromolar concentrations of these compounds are only sufficient to alter the $\mathrm{pH}$ of the DV and inhibit parasite development, a significantly higher dose is likely required to permeabilize the DV membrane. This explains why an approximately tenfold higher concentration $(100-200 \mu \mathrm{M})$ is needed to induce the PCD features earlier observed.

Taken together, these studies on lysosomotropic compounds present for the first time, clear evidence that druginduced DV destabilization can trigger PCD to occur similarly in both CQ-resistant and -sensitive P. falciparum. Although

Figure 7 Inhibitory concentration determination for lysosomotropic compounds. $\mathrm{IC}_{50}$ determination was carried out on (a) 3D7, (b) $7 \mathrm{G} 8$ and (c) K1 parasites that were incubated for $48 \mathrm{~h}$ with various concentrations of the test compounds. Compounds tested were CQ, DSP, CPZ, PMZ and $4 \mathrm{HT}$. Parasitemia was determined using Hoechst staining and flow cytometric analyses 
these compounds cause lysosomal damage to mammalian cells at the same concentration that they induce DV destabilization in $P$. falciparum, analogues of these compounds or some other parasite DV-specific compounds may be developed to eventually become functional antimalarials.

In summary, we show that the later stages of the CQ-induced PCD pathway are both $\mathrm{Ca}^{2+}$-dependent and transcriptionally regulated in $P$. falciparum. Additionally, it is demonstrated for the first time that selective permeabilization of the DV membrane occurs at high micromolar concentrations of $C Q$ and is an important upstream event in the PCD pathway. This permeabilization is shown to be rapid, abrupt and can occur without rupture of the DV membrane, reminiscent of lysosome-mediated cell death in mammalian cells. As micromolar concentrations of $\mathrm{CQ}$ are only found in the plasma immediately after the initial loading dose is administered, this may be a clinically relevant yet uncharacterized antimalarial mechanism of the drug that will rapidly clear the mature stages of the parasite. Evidence that DV destabilization can be induced by other 'non-antimalarial' compounds was also presented, and DV permeabilization was associated with PCD features. Finally, CQ-sensitive and -resistant parasites were also shown to succumb to these lysosomotropic compounds with hallmark PCD features. This opens up new possibilities for the development of a novel class of drugs, which exerts their antimalarial effect through compromising the DV membrane's integrity.

\section{Materials and Methods}

Parasite culture. A CQ-sensitive laboratory strain of $P$. falciparum, 3D7 (MRA-102, MR4; ATCC, Manassas, VA, USA), and CQ-resistant strains 7G8 (MRA-154, MR4; ATCC) and K1 (MRA-159, MR4; ATCC), were cultured continuously as previously described. ${ }^{4}$ Cultures of $\sim 7-10 \%$ parasitemia were used, with parasites being in the late-ring stage (22-26 h after invasion) during the administration of inhibitor and drugs unless otherwise stated.

Preparation of cell death inducers and treatments. Chloroquine diphosphate, VP, diltiazem, DSP, CPZ, PMZ, propranolol and chlorpheniramine (all from Sigma-Aldrich, Dorset, UK) were prepared fresh for each experiment by dissolving in PBS and filter sterilizing. Stock solutions of LL-OMe, norfloxacin, ciprofloxacin, miltefosine and vincristine (all from Sigma-Aldrich) were dissolved in DMSO and stored at $-20^{\circ} \mathrm{C}$. Stock solution of $4 \mathrm{HT}$ (Sigma-Aldrich) were dissolved in ethanol and stored at $-20^{\circ} \mathrm{C}$. CM-CQ was synthesized as previously described, ${ }^{4}$ dissolved in DMSO and stored at $-20^{\circ} \mathrm{C}$. Unless otherwise stated, parasitized erythrocytes were incubated for 4 or $10 \mathrm{~h}$ in these inducers before being washed twice with MCM and assaying for apoptotic features. Vehicle controls consisted of equivalent amounts of DMSO or PBS.

RNA preparation and reference pool. Microarray oligonucleotide design, spotting, parasite RNA purification, cDNA synthesis, Cy Dye labelling and hybridizations were performed as previously described. ${ }^{37}$ Samples per time-point were subjected to Cy Dye switching to eliminate any bias in labelling. Samples for individual time-points were hybridized against a reference pool that contained RNA samples representing all the developmental erythrocytic stages of the parasite. A total of $4 \mu \mathrm{g}$ of sample RNA per time-point was hybridized against $4 \mu \mathrm{g}$ of reference RNA were used for each microarray, and hybridizations were incubated at $60^{\circ} \mathrm{C}$ for $16 \mathrm{~h}$.

Microarray acquisition and quality control. Data from each time-point were acquired and analyzed on a GenePix Pro 4.0. (Axon, Sunnyvale, CA, USA), and the ratios normalized for the swapped Cy Dye replicates. The data were then reformatted using MEV (http://www.tm4.org/mev) and normalized using MIDAS (http://www.tm4.org/midas.html). Briefly, a scalar normalization factor was calculated for each array using unflagged features with median intensities $>0$ for each channel and a pixel regression correlation coefficient $\geqslant 0.75$. Quality spots were retained based on the log2 ratio for array features that were unflagged and had a sum of median intensities greater than the local background plus two standard deviations of the background were extracted from the database for further analysis. The ratios were then averaged for each time-point replicate.

Real-time RT-PCR. Genomic DNA contamination from purified total RNA was removed with the TURBO DNA-free Kit (Ambion, Austin, TX, USA) according to the manufacturer's protocol. Amplification was performed using the Maxima $\mathrm{SyBr}$ Green 2X Master mix (Fermentas, Glen Burnie, MD, USA) and analyzed on an ABI 7500 thermocycler (Applied Biosystems, Carlsbad, CA, USA). Primer sequences for the candidate genes can be found in Supplementary Data (Supplementary Table S5). The absolute amount of transcripts were quantified relative to the standard curve and normalized to actin as a normalization housekeeping gene. The unpaired $T$-test was used to determine the significance of the differences between biological triplicates and a $P$-value of $<0.05$ was reported.

\section{Generation of PPC knockout}

The pARL-STEVOR ${ }^{\text {full }}$ vector ${ }^{38}$ was linearized at the $B g l l l$ and Avrl sites to excise the existing STEVOR sequence. A fragment encoding the $5^{\prime}$-UTR together with the first exon of PPC gene (PFL2290w) was amplified using the PFL2290w_Bglll (5'-AGTCAGATCTGCACCATCACATTTTACAGTCC-3') and PFL2290w_Avrll ( $5^{\prime}$-AGTCCCTAGGTGGGTTTAAGTTATCCAAATTTCT- $3^{\prime}$ ) primers to create the pARL-PPC targeting vector. Parasites were transfected with $100 \mu \mathrm{g}$ plasmid DNA and drug resistant transfectants selected with $5 \mathrm{~nm}$ WR99210. ${ }^{39}$

Southern blotting. The PPC probe was generated via PCR amplification using the PFL2290w_Bglll and PFL2290w_Avrll primers (Supplementary Data, Supplementary Table S5) with $10 \mathrm{nM}$ of dUTP-DIG (Roche, Indianapolis, IN, USA). In all, $3 \mu \mathrm{g}$ of genomic DNA was digested with both EcoRV and Avrll restriction enzymes (New England Biolabs, Ipswich, MA, USA) before loading onto a $0.8 \%$ agarose gel. The size-fractionated samples were transferred onto a Zeta-Probe GT membrane (Bio-Rad, Hercules, CA, USA) via capillary transfer using $0.4 \mathrm{M} \mathrm{NaOH}$, and overnight hybridization was performed at $42^{\circ} \mathrm{C}$. All prehybridization, stringency washes and colorimetric development were performed using the NBT/BCIP DIG-High Primer DNA Labelling and Detection Starter Kit (Roche) as per the manufacturer's protocol.

Inhibitor preparation and treatments. Calpastatin was purchased from Calbiochem (La Jolla, CA, USA) and dissolved in PBS. Q-VD-OPh was purchased from SM-Biochemicals (Anaheim, CA, USA) and dissolved in DMSO and stored at $-20^{\circ} \mathrm{C}$. All other assayed cell death inhibitors were all purchased from Sigma-Aldrich and include BAPTA-AM, PBN, cycloheximide, actinomycin D and bafilomycin $\mathrm{A} 1$, all dissolved in DMSO and stored at $-20^{\circ} \mathrm{C}$, as well as L-glutathione and Mannitol that were prepared fresh each time and dissolved in PBS. Working solutions were obtained by diluting the stock concentration with MCM just before administration. Parasite cultures were preincubated with inhibitors for $30 \mathrm{~min}$ before drug treatment. The final inhibitor concentrations are as indicated in each study. Vehicle control consisted of equivalent amounts of DMSO and/or ethanol in accordance with solvent amounts used in various inhibitor treatments.

Costaining with $\mathrm{JC}-1$ and Hoechst. Cell permeable lipophilic cationic probe JC-1 (Molecular Probes, Eugene, OR, USA), also known as 5,5',6,6'tetrachloro-1,1',3,3'-tetraethyl-benzimidazolylcarbocyanine iodine, normally has green fluorescence $(525 \mathrm{~nm})$ but aggregates at high transmembrane potential of functional mitochondria to emit an orange-red fluorescence (excitation maximum at $590 \mathrm{~nm}$ ). ${ }^{40}$. Hoechst 33342 (Invitrogen, Eugene, OR, USA) is a lipophilic DNAbinding fluorescent stain that is excited by ultraviolet light $(350 \mathrm{~nm})$, and emits blue fluorescence signal $(461 \mathrm{~nm})$. In all, $200 \mu$ l of parasitized cultures were plated into flat-bottom 96-well plates and resuspended in a staining solution consisting of $6 \mu \mathrm{M}$ of JC- 1 and $0.8 \mu \mathrm{g} / \mathrm{ml}$ of Hoechst dissolved in MCM. Plates were stored for $30 \mathrm{~min}$ at $37^{\circ} \mathrm{C}$ before the cells were resuspended three times in PBS and analyzed by flow cytometry. Forward- and side-scatter profiles were used to distinguish both infected and uninfected erythrocytes from any debris. Gating for infected erythrocytes with sub-G1 Hoechst staining has been described previously. ${ }^{4}$ Having gated for all parasitized erythrocytes, the scatter-plot of $\mathrm{JC} 1$ (red) and JC1 (green) was plotted and the healthy control was used to ascertain the population with strong $\mathrm{JC} 1$ (red) signal indicative of functional mitochondria. 
Inhibitory concentration $\left(\mathbf{I C}_{50}\right)$ determination. Parasitized cultures (ring stage) diluted with fresh erythrocytes and MCM to $2 \%$ parasitemia and $1.25 \%$ hematocrit were incubated with various concentrations of test substances for $48 \mathrm{~h}$. To determine parasitemia, cultures were stained with Hoechst 33342 and analyzed by flow cytometry. Plotting of the dose-response curve as well as the computation of the $\mathrm{IC}_{50}$ was done with GraphPad Prism 5 demo version using a four-parameter logistic curve (variable slope).

Flow cytometric analyses. Cell numbers and fluorescence intensity after staining with $\mathrm{JC}-1$ and Hoechst were assayed by a high-throughput flow cytometer (BD LSRII Special Order System; BD, San Jose, CA, USA). JC-1 stain was excited with $488 \mathrm{~nm}$ blue laser with green fluorescence being detected using 505LP 525/50BP filter (396 V), while the red fluorescence was detected using 570LP $585 / 42 B P$ filter ( $350 \mathrm{~V}$ ). For Hoechst stain, excitation was by $355 \mathrm{~nm}$ UV laser while detection utilized 450LP 450/50BP filter $(380 \mathrm{~V})$. Forward and side scatter parameters were adjusted (200 V and $154 \mathrm{~V}$, respectively) to accommodate erythrocytes and to exclude any debris. Unstained controls as well as stained healthy $3 D 7$ cultures were used to determine gates at the start of each experiment to ensure consistency. At least 150 000-200000 erythrocytes were analyzed from each sample to ensure reliability and not less than three independent experiments were performed for each data set.

Statistical analyses. All data shown are means \pm S.E.M. Statistical difference was analyzed using ANOVA and post-hoc comparison using Tukey's test. Significantly different results $(P<0.05)$ were highlighted.

Intra-cellular calcium detection. Cell-permeable calcium-sensing dye, Fluo-4-AM (Molecular Probes), fluoresces green when bound with $\mathrm{Ca}^{2+}$ and was used to detect calcium storage in the DV or its release into the parasite cytoplasm. Subsequently, this stain also acted as a surrogate marker for DV permeabilization. A final concentration of $2 \mu \mathrm{M}$ of Fluo-4-AM was added to parasitized erythrocytes and incubated at $37^{\circ} \mathrm{C}$ for $30 \mathrm{~min}$. Cells were washed twice with PBS and resuspended to the original volume before viewing under a confocal microscope. At least $30-50$ parasitized cells were counted for each condition as stated in each experiment.

Confocal microscopy and single-cell tracking. Confocal imaging was done using Olympus Fluoview FV1000 (Tokyo, Japan) equipped with solid state and Argon ion lasers tuned to $405 \mathrm{~nm}$ and $488 \mathrm{~nm}$, respectively. Images were captured using Olympus Fluoview version 1.6b. For enumeration purposes, images of at least 30-50 parasitized erythrocytes were screened per condition, as stated in each experiment. Briefly, cells on a wet-mount were visualized under $\times 100$ magnification and $\times 5$ zoom with the following calibrations: $2.0 \mu$ s/Pixel sampling speed, line Kalman integration, $488 \mathrm{~nm}$ laser (for Fluo-4-AM) at $713 \mathrm{~V}$ and transmissivity of $10.0 \%, 405 \mathrm{~nm}$ laser (for CM-CQ and Hoechst) at $605 \mathrm{~V}$ and transmissivity of $3.0 \%$. These parameters were used in all experiments to ensure consistency. In single-cell tracking experiments, chambered glass slides were pretreated for $5 \mathrm{~min}$ with $1: 8$ dilution of poly-L-lysine (Sigma-Aldrich) and left to dry for $1 \mathrm{~h}$ at $60^{\circ} \mathrm{C}$. Cultures that were prestained with Fluo-4-AM were diluted to a final hematocrit of $0.1 \%$ and $1 \mathrm{ml}$ was added per chamber. A vehicle control or $3 \mu \mathrm{M}$ of $C Q$ was then administered while the cells were given time to settle to the base of the chamber. The viewing stage was perfused with standard parasite culture gas mixture and kept at $37^{\circ} \mathrm{C}$ for the entire period of viewing. At $2 \mathrm{~h}$ after $\mathrm{CQ}$ was added, micrographs were captured every 1 or $3 \mathrm{~min}$ for the next $2 \mathrm{~h}$, using a reduced laser transmissivity of $1.0 \%$ to reduce photobleaching. Fluorescence intensity tracing of parasite cross-sections were carried out using ImageJ $1.44 \mathrm{p}$ software (National Institutes of Health, Bethesda, MD, USA).

Transmission electron microscopy. Erythrocyte-free parasites were first isolated by saponin enrichment as previously described ${ }^{4}$ and washed twice in cold PBS. Cells were then fixed $24 \mathrm{~h}$ in $2 \%$ glutaraldehyde (w/v PBS) at $4{ }^{\circ} \mathrm{C}$. After washing three times in cold PBS, cells were post-fixed for $1 \mathrm{~h}$ with $1 \%$ osmium tetroxide (w/v PBS) with $1 \%$ potassium ferro-cyanide followed by dehydration with a graded ethanol series. Thereafter, cells were infiltrated and embedded with LR-White resin (London Resin Company, London, UK) at $60^{\circ} \mathrm{C}$ for 4 days and ultrathin sections (70-90 $\mathrm{nm}$ thickness) were prepared using UltraCut E microtome (Reichert-Jung, Wein, Austria). These sections were then collected on copper mesh grids, stained a second time with $1 \%$ osmium tetroxide for $5 \mathrm{~min}$, rinsed, treated with uranyl acetate for $8 \mathrm{~min}$, rinsed, and in lead citrate for $8 \mathrm{~min}$ before final rinsing. Sections were then examined using an EM208S transmission electron microscope
(Phillips, Eindhoven, The Netherlands) and DigitalMicrograph software v1.82.365 (Pleasanton, CA, USA).

\section{Conflict of interest}

The authors declare no conflict of interest.

Acknowledgements. Research from Kevin Tan's laboratory has been generously supported by a grant from the National Medical Research Council, Infectious Disease Program and the National Research Foundation. C.J.H thanks the National University of Singapore for his Graduate Scholarship. RNA extraction was kindly performed by Chong Guo Lin Alvin and Vivien Loon Ming Fang from the Department of Microbiology, NUS. Coumarin-tagged chloroquine was donated from Dr. Martin J. Lear, Santosh R. Kotturi and Kunal Mahajan from the Department of Chemistry, NUS. The use of the flow cytometry facility of the Singapore MIT Alliance for Research and Technology (SMART-ID IRG), Confocal Microscopy Unit at NUMI and Transmission Electron Microscopy Unit at the Department of Microbiology is appreciated, with special thanks to Loh Siew Chin, Lee Shu Ying, Wei Ann and Josephine Howe. We also thank MR4 for providing us with malaria parasites contributed by Daniel Carucci and Alister Craif (3D7), and Dennis Kyle (7G8 and K1).

1. World Health Organization. Ten Facts on Malaria. World Health Organization, 2009. Available online at http://www.who.int/features/factfiles/malaria/en/index.html.

2. Dondorp AM, Nosten F, Yi P, Das D, Phyo AP, Tarning J et al. Artemisinin resistance in Plasmodium falciparum malaria. N Engl J Med 2009; 361: 455-467.

3. White NJ. The role of anti-malarial drugs in eliminating malaria. Malar J 2008; 7 (Suppl 1): S8.

4. Ch'ng JH, Kotturi SR, Chong AL, Lear MJ, Tan KW. A programmed cell death pathway in the malaria parasite Plasmodium falciparum has general features of mammalian apoptosis but is mediated by clan CA cysteine proteases. Cell Death Dis 2010; 1: e26.

5. Deponte M. Programmed cell death in protists. Biochim Biophys Acta 2008; 1783: 1396-1405.

6. Totino PR, Daniel-Ribeiro CT, Corte-Real S, de Fatima Ferreira-da-Cruz M. Plasmodium falciparum: erythrocytic stages die by autophagic-like cell death under drug pressure. Exp Parasitol 2008; 118: 478-486.

7. Hurd $\mathrm{H}$, Carter $\mathrm{V}$. The role of programmed cell death in Plasmodium-mosquito interactions. Int J Parasitol 2004; 34: 1459-1472.

8. Meslin B, Barnadas C, Boni V, Latour C, De Monbrison F, Kaiser K et al. Features of apoptosis in Plasmodium falciparum erythrocytic stage through a putative role of PfMCA1 metacaspase-like protein. J Infect Dis 2007; 195: 1852-1859.

9. Oakley MS, Kumar S, Anantharaman V, Zheng H, Mahajan B, Haynes JD et al. Molecular factors and biochemical pathways induced by febrile temperature in intraerythrocytic Plasmodium falciparum parasites. Infect Immun 2007; 75: 2012-2025.

10. Kumar S, Guha M, Choubey V, Maity P, Srivastava K, Puri SK et al. Bilirubin inhibits Plasmodium falciparum growth through the generation of reactive oxygen species. Free Radic Biol Med 2008; 44: 602-613.

11. Al-Olayan EM, Williams GT, Hurd H. Apoptosis in the malaria protozoan, Plasmodium berghei: a possible mechanism for limiting intensity of infection in the mosquito. Int $J$ Parasitol 2002; 32: 1133-1143.

12. Ali M, Al-Olayan EM, Lewis $\mathrm{S}$, Matthews $\mathrm{H}, \mathrm{Hurd} \mathrm{H}$. Naturally occurring triggers that induce apoptosis-like programmed cell death in Plasmodium berghei ookinetes. PLoS One 2010; 5: e12634.

13. Nyakeriga AM, Perlmann H, Hagstedt M, Berzins K, Troye-Blomberg M, Zhivotovsky B et al. Drug-induced death of the asexual blood stages of Plasmodium falciparum occurs without typical signs of apoptosis. Microbes Infect 2006; 8: 1560-1568.

14. Porter H, Gamette MJ, Cortes-Hernandez DG, Jensen JB. Asexual blood stages of Plasmodium falciparum exhibit signs of secondary necrosis, but not classical apoptosis after exposure to febrile temperature (40 C). J Parasitol 2008; 94: 473-480.

15. Biagini GA, Bray PG, Spiller DG, White MR, Ward SA. The digestive food vacuole of the malaria parasite is a dynamic intracellular Ca2+ store. J Biol Chem 2003; 278: 27910-27915.

16. Farias SL, Gazarini ML, Melo RL, Hirata IY, Juliano MA, Juliano L et al. Cysteineprotease activity elicited by $\mathrm{Ca} 2+$ stimulus in Plasmodium. Mol Biochem Parasitol 2005; 141: 71-79.

17. Gazarini ML, Sigolo CA, Markus RP, Thomas AP, Garcia CR. Antimalarial drugs disrupt ion homeostasis in malarial parasites. Mem Inst Oswaldo Cruz 2007; 102: 329-334.

18. Rosenthal PJ. Cysteine proteases of malaria parasites. Int $J$ Parasitol 2004; 34: 1489-1499.

19. Sajid M, McKerrow JH. Cysteine proteases of parasitic organisms. Mol Biochem Parasitol 2002; 120: 1-21. 
20. Nadanaciva S, Lu S, Gebhard DF, Jessen BA, Pennie WD, Will Y. A high content screening assay for identifying lysosomotropic compounds. Toxicol In Vitro 2010; 25: 715-723.

21. Boya P, Andreau K, Poncet D, Zamzami N, Perfettini JL, Metivier D et al. Lysosoma membrane permeabilization induces cell death in a mitochondrion-dependent fashion. J Exp Med 2003; 197: 1323-1334.

22. Boya $P$, Gonzalez-Polo RA, Poncet $D$, Andreau $K$, Vieira $H L$, Roumier $T$ et al. Mitochondrial membrane permeabilization is a critical step of lysosome-initiated apoptosis induced by hydroxychloroquine. Oncogene 2003; 22: 3927-3936.

23. Alves E, Bartlett PJ, Garcia CR, Thomas AP. Melatonin and IP3-induced Ca2+ release from intracellular stores in the malaria parasite Plasmodium falciparum within infected red blood cells. J Biol Chem 2011; 286: 5905-5912.

24. Beraldo FH, Garcia CR. Products of tryptophan catabolism induce Ca2+ release and modulate the cell cycle of Plasmodium falciparum malaria parasites. J Pineal Res 2005; 39 : 224-230.

25. Hotta CT, Gazarini ML, Beraldo FH, Varotti FP, Lopes C, Markus RP et al. Calciumdependent modulation by melatonin of the circadian rhythm in malarial parasites. Nat Cell Biol 2000; 2: 466-468.

26. Gazarini ML, Garcia CR. The malaria parasite mitochondrion senses cytosolic $\mathrm{Ca} 2+$ fluctuations. Biochem Biophys Res Commun 2004; 321: 138-144.

27. Vinayak S, Mittra P, Sharma YD. Wide variation in microsatellite sequences within each Pfcrt mutant haplotype. Mol Biochem Parasitol 2006; 147: 101-108.

28. Bursch W. The autophagosomal-lysosomal compartment in programmed cell death. Cell Death Differ 2001; 8: 569-581.

29. Broker LE, Kruyt FA, Giaccone G. Cell death independent of caspases: a review. Clin Cancer Res 2005; 11: 3155-3162.

30. Boya P, Kroemer G. Lysosomal membrane permeabilization in cell death. Oncogene 2008 27: $6434-6451$

31. Johansson AC, Appelqvist H, Nilsson C, Kagedal K, Roberg K, Ollinger K. Regulation of apoptosis-associated lysosomal membrane permeabilization. Apoptosis 2010; 15: 527-540.

32. Bidere N, Lorenzo HK, Carmona S, Laforge M, Harper F, Dumont C et al. Cathepsin D triggers Bax activation, resulting in selective apoptosis-inducing factor (AIF) relocation in
T lymphocytes entering the early commitment phase to apoptosis. J Biol Chem 2003; 278: 31401-31411.

33. Okonkwo PO, Eta El. Simultaneous determination of chloroquine and metronidazole in human biological fluid by high pressure liquid chromatography. Life Sci 1988; 42: 539-545.

34. Augustijns $P$, Geusens $P$, Verbeke N. Chloroquine levels in blood during chronic treatment of patients with rheumatoid arthritis. Eur J Clin Pharmacol 1992; 42: 429-433.

35. Jaeger A, Flesch F. Chloroquine. IPCS, 1994. Available online at http://www.inchem.org/ documents/pims/pharm/chloroqu.htm

36. Foley M, Tilley L. Quinoline antimalarials: mechanisms of action and resistance and prospects for new agents. Pharmacol Ther 1998; 79: 55-87.

37. Bozdech Z, Zhu J, Joachimiak MP, Cohen FE, Pulliam B, DeRisi JL. Expression profiling of the schizont and trophozoite stages of Plasmodium falciparum with a long-oligonucleotide microarray. Genome Biol 2003; 4: R9.

38. Przyborski JM, Miller SK, Pfahler JM, Henrich PP, Rohrbach P, Crabb BS et al. Trafficking of STEVOR to the Maurer's clefts in Plasmodium falciparum-infected erythrocytes. EMBOJ 2005; 24: 2306-2317.

39. Crabb BS, Rug M, Gilberger TW, Thompson JK, Triglia T, Maier AG et al. Transfection of the human malaria parasite Plasmodium falciparum. Methods Mol Biol 2004; 270: 263-276.

40. Smiley ST, Reers M, Mottola-Hartshorn C, Lin M, Chen A, Smith TW et al. Intracellular heterogeneity in mitochondrial membrane potentials revealed by a J-aggregate-forming lipophilic cation JC-1. Proc Natl Acad Sci USA 1991; 88: 3671-3675.

Cell Death and Disease is an open-access journal published by Nature Publishing Group. This work is licensed under the Creative Commons Attribution-Noncommercial-No Derivative Works 3.0 Unported License. To view a copy of this license, visit http://creativecommons.org/licenses/by-nc-nd/3.0/

Supplementary Information accompanies the paper on Cell Death and Disease website (http://www.nature.com/cddis) 